\title{
Universal Gift Form and Instructions
}

Prepared by the Committee on Manuscripts Collections of the ACRL Rare Books and Manuscripts Section. Approved by the ACRL Board of Directors on January 23, 1975.

\section{Universal Gift Form}

\section{[Board of Trustees of the} Anonymous Athenaeum]

I/We hereby give, transfer, and deliver all of my/our right, title and interest in and to the property described below to the [Board of Trustees of the Anonymous Athenaeum] as an unrestricted gift and dedicate to the public without restriction and thereby place in the public domain whatever literary rights $\mathrm{I} /$ we may possess to this property.

Dated this__ day of__ , 19_:

1.

\begin{tabular}{l} 
Signature \\
\hline Address
\end{tabular}

2.

\section{Signature}

Address

3.

Signature

Address

The [Board of Trustees of the Anonymous Athenaeum] hereby accepts and acknowledges as an unrestricted gift to the [Library of the Anonymous Athenaeum] the collection described below and agrees to administer it in accordance with its established policies.

Dated this day of 19

Accepted by: Signature Title

Description of the collection:

General Instructions

For Univemsal Gift Form

Any deed of gift, or letter, if it incorporates the necessary elements, is a legally recognized document which effectively transfers title for manuscripts or other items from a donor to a receiving institution. Such deed of gift formalizes the transaction and makes explicit the agreement between the parties. Certain elements must be part of any such deed of gift but additional variations are possible. They will depend on the nature of the gift, the desires of the two parties as expressed in the verbal agreement between them, and the need to spell out any unique conditions and/or restrictions placed on the material. The following elements, however, are considered basic: (1) the date of execution, (2) the name of the donor, (3) a description of the items transferred, (4) the signature of the donor, and (5) acceptance of ownership and responsibility by the institution as evidenced by a statement to that effect and an authorized signature.

It must be understood that an intention on the part of the donor to give material, its acceptance by the institution, and the recording of that agreement and transfer in some written document constitute a transfer only of the physical property. Literary rights to the material remain with the party to whom they belong, and this may, or may not, be the donor of the material. It is generally considered desirable at the time of transfer to acquire whatever literary rights the donor possesses, but it is necessary to include a statement covering such transfer in the deed of gift, if this is to be effected. An institution may elect to have those rights transferred to the institution itself or it may include a statement specifically dedicating them to the public.

The question as to whether one should include a place for possible restrictions with regard to access to materials in a form developed to serve as a deed of gift is a knotty one. It is sometimes considered unwise to trigger the imposition of restrictions which might not otherwise occur to a donor. On the other hand, there may be certain situations which suggest, or indeed call for, restrictions, and it would be remiss of a curator not to point this out.

In general, however, the interests of the institution and its patrons will be best served by transferring the material in a manner which provides the widest leeway for the institution in the administering and servicing of the manuscripts. This will usually call for a simple and straightforward deed of gift, and it is that basic form which is suggested here, with the proviso that the institution and the curator must be aware of the range of possible variations.

It should also be pointed out that not only will the requirements vary with different insti- 
tutions and with each individual gift, but also there may be a considerable variance in local legal requirements, and these will need to be checked. It would seem to be a cardinal rule that an institution or curator should seek some legal advice before instituting and using a form as a deed of gift. It should also be recognized that no form will cover every situation, and it will at times be necessary to draw up a document tailored specifically to the requirements of a particular case.

Although some institutions will include other matters in a deed of gift, there are advantages to keeping the form as relatively brief and uncomplicated as possible. Such matters as (1) the disposition of unwanted material or duplicates, (2) the handling of printed material, (3) the photoreproduction of the material for scholarly use, (4) the handling of publicity, and (5) the mechanism for permission to publish should be handled through correspondence or by other means.

If it is likely that in the future there will be additional material donated which is related to the initial gift, the deed of gift might properly speak to that matter. If restrictions are agreed on between the donor and the recipient and stated in the agreement, there should also be stated a terminal date and an understanding of where the authority for continuation or removal of those restrictions lies in the event of the donor's death.

All of these comments as well as the sample deed of gift refer to situations in which the physical property is being given outright to the institution, whether or not the literary rights in the possession of the donor accompany and are part of the gift. There are, of course, situations in which a donor merely wishes to deposit the material in an institution. In such cases the understanding is usually that outright donation will generally follow, but the curator must be aware that it is in no way inevitable. In such cases the offer should be scrutinized carefully and matters such as the availability of his material for scholarly use, photoreproduction, and publication should be accurately understood between the donor and the institution. An entirely separate agreement of deposit which speaks to the necessary points should be developed and executed in the rare cases where such deposit is acceptable to the institution and outright gift of the material at the time does not seem possible.

Reprints of this article are available from the ACRL office, $50 \mathrm{E}$. Huron St., Chicago, IL 60611 .

\section{Draft Statement on the Reproduction of Manuscripts and Archives for Commercial Purposes}

The following statement was prepared by the Committee on Manuscripts Collections of the ACRL Rare Books and Manuscripts Section. It will be considered for approval by the ACRL Board of Directors at the 1975 Annual Conference in San Francisco. All comments and suggestions for revision should be sent to the chairman of the committee, Clyde C. Walton, Director of Libraries, Northern Illinois University, DeKalb, Illinois 60115.

1. It is the responsibility of libraries, archives, or manuscript repositories to facilitate access to original collections by permitting commercial publishing companies to reproduce, reprint, or otherwise publish certain collections in its possession, unless:

a. the physical condition of the originals prohibits reproduction

b. there are legal restrictions which prohibit or limit reproduction of the originals.

2. No repository shall be expected to reproduce a complete manuscript collection or archival record group.

3. The commercial publisher shall agree to the following conditions: a. Permission. (1) The publisher shall be responsible for compliance with all copyright and other legal requirements applicable to reproduction of the material borrowed and will obtain (and will deliver to the owning institution a duplicate executed counterpart of) all such consents, licenses, and other instruments as may be necessary for such compliance. (2) The publisher shall agree to indemnify and hold harmless the owning institution, its officers and employees, any and all of them, against and from any liability, loss, cost or expense whatsoever, including attorney's fees, which the owning institution, its officers and employees, any and all of them, may at any time incur arising out of or relating to the reproduction of any of its manuscripts.

b. Acknowledgment. The publisher shall cause the reproduction of any manuscript collection or archival record group to show that it has been made from an original in the library of the owning institution.

c. Quality of Reproduction. The publisher 